\title{
Does maternal exposure to an environmental stressor affect offspring response to predators?
}

\author{
Brian D. Todd · Christine M. Bergeron • \\ Mark J. Hepner · John N. Burke $\cdot$ William A. Hopkins
}

Received: 3 June 2010 / Accepted: 2 March 2011 / Published online: 18 March 2011

(C) The Author(s) 2011. This article is published with open access at Springerlink.com

\begin{abstract}
There is growing recognition of the ways in which maternal effects can influence offspring size, physiological performance, and survival. Additionally, environmental contaminants increasingly act as stressors in maternal environments, possibly leading to maternal effects on subsequent offspring. Thus, it is important to determine whether contaminants and other stressors can contribute to maternal effects, particularly under varied ecological conditions that encompass the range under which offspring develop. We used aquatic mesocosms to determine whether maternal effects of mercury $(\mathrm{Hg})$ exposure shape offspring phenotype in the American toad (Bufo americanus) in the presence or absence of larval predators (dragonfly naiads). We found significant maternal effects of $\mathrm{Hg}$ exposure and significant effects of predators on several offspring traits, but there was little evidence that maternal effects altered offspring interactions with predators. Offspring from $\mathrm{Hg}$-exposed mothers were $18 \%$ smaller than those of reference mothers. Offspring reared with predators were $23 \%$ smaller at metamorphosis than those reared without predators. There was also evidence of reduced larval survival when larvae were reared with pre-
\end{abstract}

Electronic supplementary material The online version of this article (doi:10.1007/s00442-011-1961-9) contains supplementary material, which is available to authorized users.

B. D. Todd · C. M. Bergeron · M. J. Hepner · J. N. Burke ·

W. A. Hopkins

Department of Fish and Wildlife Conservation,

Virginia Tech, 100 Cheatham Hall, Blacksburg, VA 24061, USA

B. D. Todd $(\bowtie)$

Department of Wildlife, Fish, and Conservation Biology,

University of California, Davis,

One Shields Ave, Davis, CA 95616, USA

e-mail: btodd@ucdavis.edu dators, but this was independent of maternal effects. Additionally, 5 times more larvae had spinal malformations when reared without predators, suggesting selective predation of malformed larvae by predators. Lastly, we found a significant negative correlation between offspring survival and algal density in mesocosms, indicating a role for top-down effects of predators on periphyton communities. Our results demonstrate that maternal exposure to an environmental stressor can induce phenotypic responses in offspring in a direction similar to that produced by direct exposure of offspring to predators.

Keywords Amphibian declines - Maternal effects . Maternal transfer $\cdot$ Mercury $\cdot$ Odonates

\section{Introduction}

Interest in the pervasiveness of maternal effects on offspring fitness has increased in recent decades (e.g., Mousseau et al. 2009). This interest has grown in part because of the increasing number of studies documenting the persistent and often significant repercussions maternal effects can have on offspring. For example, maternal effects often influence offspring size, physiological performance, and survival (Mousseau and Fox 1998), which in turn have important ecological consequences for population demography (e.g., Pontier et al. 1993). These maternal effects occur partly because small perturbations early in ontogeny can permanently alter offspring developmental trajectories (Bernardo 1996). Consequently, a mother's environment can exert epigenetic effects on offspring that may ultimately affect development, behavior, survival, and the ecological interactions of offspring. This is also true when environmental stressors such as contaminants comprise part of a 
mother's environment, especially when contaminants have developmental or neurological impacts (e.g., Ohlendorf et al. 1989; Fry 1995).

As humans continue to alter and modify habitats globally, contaminants increasingly act as stressors in the environment of many organisms. As with other maternal effects, maternal exposure to contaminants can have strong effects on offspring because of the sensitivity of offspring during early development. For example, contamination of the Sacramento River with polybrominated diphenyl esthers (PBDEs) has led to bioaccumulation in striped bass (Morone saxatilis), resulting in abnormal development and retarded growth of offspring (Ostrach et al. 2008). Similarly, the accumulation of mercury $(\mathrm{Hg})$ in both birds and fish has reduced survival and altered behavior in subsequent offspring (Heinz 1976; Alvarez et al. 2006). These studies reveal an important consequence of maternal effects from exposure to environmental stressors, but few researchers have examined whether these maternal effects can affect offspring when combined with other environmental stressors, a scenario more typical of natural environments.

Amphibians serve as a classic vertebrate system for the study of both maternal and environmental contributions to offspring phenotype (e.g., Morin 1983; Wilbur 1987; Resetarits and Wilbur 1989). For example, Semlitsch and Gibbons (1990) investigated maternal contributions to egg size and found that larger eggs resulted in larger offspring, a trait that persisted 49 days after hatching. Additionally, there has been much work on environmental contributions to offspring phenotype in amphibians, including studies on the effects of larval predators (Relyea 2007), effects of conspecific densities (e.g., Scott 1994), and the effects of environmental contaminants (Boone and James 2005). In contrast, there has been little research on the ways in which maternal contaminant exposure can shape offspring phenotype in amphibians. However, at least one study has demonstrated maternal effects that include reduced hatching success and increased developmental abnormalities in offspring from mothers with elevated strontium and selenium in their tissues (Hopkins et al. 2006). Given that amphibians often forage and breed in contaminated riparian and wetland habitats and can accumulate significant contaminant body burdens (e.g., Hopkins et al. 2006; Unrine et al. 2007; Wu et al. 2009; Bergeron et al. 2010a), they can provide useful insights into the ways in which maternal effects of environmental stressors shape offspring phenotypes, particularly when combined with other stressors such as competitors or predators.

Predatory odonates can alter larval phenotypes in amphibians with important consequences for individual fitness (reviewed in Relyea 2007). Additionally, $\mathrm{Hg}$ has developmental and neurological toxicity to many vertebrates (Myers et al. 1997), and can consequently affect fitness (Tan et al. 2009). In an earlier study, Bergeron et al. (2010b) demonstrated that female American toads (Bufo americanus) that inhabit a Hg-contaminated floodplain accumulate $\mathrm{Hg}$ and transfer the contaminant to their eggs. Our goal in this study was to examine the maternal effects of $\mathrm{Hg}$ accumulation on offspring in the presence and absence of predatory odonates. We used a factorial experimental design to test the effects of maternal $\mathrm{Hg}$ exposure in the presence or absence of odonates. We predicted maternal $\mathrm{Hg}$ exposure would have significant effects on the survival and development of larval American toads. We also predicted that effects of maternal $\mathrm{Hg}$ exposure would be greater when combined with the threat of predation from odonates. Finally, we predicted that a reduction in offspring survival would increase algae in the experimental mesocosms via reduced grazing pressure, demonstrating a topdown ecological role of anuran larvae and the possible indirect ecological consequences of reduced larval survival caused by maternal effects, odonates, or both.

\section{Materials and methods}

\section{Field methods}

On 17 and 18 April 2009, we collected reproductive pairs of American toads that had entered amplexus but had not yet begun ovipositing in breeding pools along the South River floodplain (Waynesboro, VA, USA), both upstream and downstream of a historic $\mathrm{Hg}$ contamination source (see Bergeron et al. 2010a for additional information). We brought the breeding pairs indoors within $2 \mathrm{~h}$ and placed each pair in a shallow bin with dechlorinated tap water and allowed them to oviposit overnight. The next morning, we removed the adult toads from the bins and added additional dechlorinated tap water to the egg masses. We recorded post-oviposition mass of each female at this point. We next removed a small portion of each egg mass (approximately 500 eggs) and froze them for subsequent $\mathrm{Hg}$ analysis. We collected $\sim 0.25 \mathrm{~mL}$ whole blood from each anesthetized mother via cardiocentesis to nondestructively estimate female total $\mathrm{Hg}$ ( $\mathrm{THg}$ ) concentrations following the methods of Bergeron et al. (2010a). We marked each toad by toe-clipping and released all adult toads at their original points of capture within $24 \mathrm{~h}$ after they recovered from anesthesia.

Since $\mathrm{Hg}$ concentrations in female blood are closely correlated with $\mathrm{Hg}$ concentrations in their eggs (Bergeron et al. 2010b), we analyzed female blood $\mathrm{Hg}$ concentrations before the eggs hatched to confirm the correct placement of eggs into either reference treatments (hatchlings from females with blood $\mathrm{Hg}$ concentrations $<250 \mathrm{ng} / \mathrm{g}$, wet weight) or maternally $\mathrm{Hg}$-exposed treatments (hatchlings 
from females with blood concentrations $>1,000 \mathrm{ng} / \mathrm{g}$, wet weight). See below for details on $\mathrm{Hg}$ analytical methods. Offspring used in the reference treatments came from 5 combined clutches and offspring used in the maternally $\mathrm{Hg}$ exposed treatments came from 6 combined clutches (Electronic supplementary material, Fig. S1). Prior to the start of the experiment, we measured the mass of each of 10 larvae chosen haphazardly from each clutch to derive a representative average larval mass from each mother.

\section{Mesocosms and experimental design}

We established 32 outdoor aquatic mesocosms in 1,500-L polyethylene cattle tanks on the campus of Virginia Polytechnic Institute and Statue University (Virginia Tech) in Blacksburg, VA. On 1 March 2009, we filled each mesocosm with $475 \mathrm{~L}$ of well water and $475 \mathrm{~L}$ of dechloraminated tap water. Each mesocosm received $1 \mathrm{~kg}$ of air-dried deciduous leaf litter (50:50 poplar and oak mix) and $17 \mathrm{~g}$ of finely ground Purina Rabbit Chow ${ }^{\circledR}$ (St. Louis, MO, USA). To promote algal and periphyton growth, we spiked each mesocosm initially with $2 \mathrm{~L}$ of pond water from Pandapas Pond (Jefferson National Forest, VA) filtered through a 200$\mu \mathrm{m}$ sieve. We later repeated this procedure using water from Pandapas Pond and again using water from a permanent pond at the aquaculture facility at Virginia Tech. Before beginning the experiment, we also exchanged 20-L portions of water between each mesocosm and its four closest mesocosms on 3 separate occasions to reduce the variability in initial phytoplankton communities. Each mesocosm had a black mesh lid made of $1 \times 1 \mathrm{~mm}$ window screen that provided shade and prevented unwanted colonization by predators or competitors. Lastly, we monitored conductivity, $\mathrm{pH}$, temperature, and dissolved oxygen weekly at 0730 and 1930 hours (approximate coolest and warmest daily water temperatures, respectively) in eight randomly selected mesocosms that were followed throughout the study.

We used a $2 \times 2$ factorial design to test the effects of maternal $\mathrm{Hg}$ exposure, the presence of predatory odonates, and their interaction on American toad offspring (Electronic supplementary material, Fig. S1). On 28 April 2009, we added 100 tadpoles to each of 32 replicated mesocosms. Each 100-tadpole population of reference larvae was composed of 20 larvae from 5 reference clutches (Electronic supplementary material, Fig. S1). Each 100-tadpole population of maternally $\mathrm{Hg}$-exposed larvae drew approximately equally from 6 maternally $\mathrm{Hg}$-exposed clutches $(5$ clutches contributed 17 larvae and a 6th clutch contributed 15 larvae). At the time of their introduction to the mesocosms, tadpoles were $\sim 4$ days post-hatching. We arranged the mesocosms in a random block design so that each of the four experimental crosses was represented in each of the eight rows of outdoor mesocosms. On 8 May 2009, we added 5 predatory odonates to each of the 16 mesocosms that were to contain predators. Mesocosms with predators each received a single 1-cm-long Nehalennia spp., three 1.5-cm-long Libellula pulchella or Pachydiplax longipennis, and a single 2.5-cm-long Tramea lacerata nymph. These are broad-ranging odonates with distributions that overlap that of American toads and whose nymphs can be found in aquatic habitats in which American toads breed (Needham et al. 2000).

We monitored mesocosms daily and removed tadpoles as soon as they began metamorphosis, identified by forelimb emergence at Gosner stage (GS) 42 (Gosner 1960). All metamorphosing tadpoles were brought indoors to complete metamorphosis. We recorded the presence of injuries, spinal malformations, or dwarf limbs on each individual as it was removed from the mesocosm. Any individuals removed from mesocosms after forelimb emergence were excluded from spinal malformation analyses to avoid confusing tail curves due to tail resorption with true spinal malformations. After bringing animals indoors, we placed each individual in a separate 500-mL cup and $\sim 20 \mathrm{~mL}$ of mesocosm water with an unbleached paper towel to allow them to climb out of the water following complete tail resorption. We checked each metamorphosing tadpole every morning at 0700 hours to determine whether it had completed tail resorption (GS 46) or had died overnight. We quantified the proportion of individuals that successfully completed metamorphosis out of the original 100 in each mesocosm. We also determined mass of each tadpole at both GS 42 and GS 46 using an electronic balance. We quantified the duration of the larval period for each tadpole (i.e., time to GS 42) and the number of days it took each tadpole to completely resorb its tail (time between GS 42 and 46). Animals that were removed from mesocosms at GS 43 or later were not included in time calculations. In all cases, the mean response in each mesocosm was treated as the unit of replication. All surviving recently metamorphosed toads were humanely euthanized with buffered tricaine methane sulfonate (MS-222) and then frozen for later use in Hg-tissue analyses.

Just before peak metamorphosis on 1 June 2009, two observers blind to the experimental treatments visually examined each mesocosm and scored the relative thickness of algal growth along its walls. Each mesocosm was scored as having either no algal growth (0), some algal growth (1), or dense algal growth (2). Scores from the two independent observers were averaged and used as a measure of algal growth for each mesocosm.

\section{Sample preparation and $\mathrm{Hg}$ analyses}

Previous research on American toads from this same site demonstrated that approximately 71 and $48 \%$ of the $\mathrm{THg}$ in 
blood and eggs, respectively, is in the more toxic form, methylmercury (MeHg; Bergeron et al. 2010b). Thus, we limited $\mathrm{Hg}$ analyses to THg in this study. We homogenized whole blood from each adult American toad using a vortex mixer and report $\mathrm{THg}$ concentrations in blood on a wet weight (ww) basis. We lyophilized and homogenized eggs and metamorph carcasses and report $\mathrm{THg}$ concentrations on a dry weight ( $\mathrm{dw}$ ) basis. Percent moisture was $95.4 \pm 0.2 \%$ (mean $\pm 1 \mathrm{SE}$ of the mean hereafter) for eggs and $89.3 \pm$ $0.3 \%$ for metamorphs. We analyzed subsamples $(\sim 20 \mathrm{mg})$ for THg content by combustion-amalgamation-cold vapor atomic absorption spectrophotometry (Direct Mercury Analyzer 80; Milestone, Monroe, CT, USA) according to US Environmental Protection Agency method 7473 (USEPA 1998). For quality assurance, each group of 10-15 samples included a replicate, blank, and standard reference material (SRM; DORM-3 fish protein and DOLT-3 or DOLT-4 dogfish liver; National Research Council of Canada, Ottawa, ON). We calibrated the instrument using solid SRMs (DORM-3 and DOLT-3 or DOLT-4). Method detection limits (MDLs; 3 times standard deviation of procedural blanks) for samples were $0.38 \mathrm{ng}$, and all samples had THg concentrations that exceeded the limit. Average relative percent differences (RPD) between replicate sample analyses were $5.77 \pm 1.35 \%(n=25)$. Mean percent recoveries of THg for the SRMs, DORM-3, DOLT-3 and DOLT-4 were $103.82 \pm$ $1.15 \% \quad(n=43), \quad 99.66 \pm 0.51 \% \quad(n=12), \quad$ and $97.61 \pm$ $0.36 \%(n=30)$, respectively.

\section{Statistical analyses}

We used an analysis of variance (ANOVA) to compare masses of reference mothers and Hg-exposed mothers. We used Pearson correlations to determine whether maternal mass was correlated with mean larval mass for each clutch at the start of the experiment. We used an ANOVA to determine whether mean mass of larvae from reference clutches $(n=5)$ and maternally exposed clutches $(n=6)$ differed at the start of the experiment. For data generated in the replicated mesocosms, we calculated means for each dependent variable for each mesocosm. We used a multivariate analysis of variance (MANOVA) to test the effects of predators, maternal $\mathrm{Hg}$ exposure, and their interaction on survival to Gosner stage 46, mass at GS 42, mass at GS 46, time to reach GS 42 (larval duration), and time for tail resorption. We used inverse transformations to normalize the data for larval duration and time for tail resorption. Because the mean proportions of tadpoles having tail malformations, injuries, or stunted limbs were skewed and had heterogeneous variances among the treatments, we used non-parametric $2 \times 2$ factorial Scheirer-Ray-Hare tests to test for effects of predators, maternal $\mathrm{Hg}$ exposure, and their interaction on these dependent variables. The Scheirer-Ray-
Hare test serves as a non-parametric extension of an analysis of variance for factorial designs by modifying the model error term and $F$ statistic, resulting in a highly conservative test compared to traditional analysis of variance (Dytham 2003). Lastly, we used linear regression to examine the relationship between the number of tadpoles surviving to GS 42 and the algae score of each mesocosm. In all cases, data either met the assumptions for parametric statistical analyses or non-parametric alternative tests were used as described above.

\section{Results}

\section{Hg concentrations}

As described in the methods, clutches were allotted into either reference or contaminated treatments based on $\mathrm{Hg}$ concentrations in the blood of mothers. Reference mothers had blood $\mathrm{Hg}$ concentrations that averaged $159.5 \pm 18.6$ (mean $\pm 1 \mathrm{SE}$ ) ng/g ww compared with blood $\mathrm{Hg}$ concentrations of 2,250 $\pm 489.8 \mathrm{ng} / \mathrm{g}$ ww for contaminated mothers. Egg $\mathrm{Hg}$ concentrations from reference mothers averaged $20.6 \pm 1.3 \mathrm{ng} / \mathrm{g}$ dw compared with $149.1 \pm 17.9$ $\mathrm{ng} / \mathrm{g} \mathrm{dw}$ for eggs from contaminated mothers. However, $\mathrm{Hg}$ concentrations of all recently metamorphosed toads were low and ranged from $25.4-32.7 \mathrm{ng} / \mathrm{g} \mathrm{dw}$, demonstrating that the lack of added dietary $\mathrm{Hg}$ and a 17 -fold increase in body mass decreased $\mathrm{Hg}$-tissue concentrations to levels comparable to eggs from reference mothers.

\section{Biological endpoints}

There was evidence of smaller mass in mothers collected from the $\mathrm{Hg}$-contaminated site $\left(F_{1,9}=4.5, P=0.06\right)$. However, mean larval mass for each clutch and maternal mass were not correlated $(r=0.03, P=0.94)$ and there was no significant difference in mean larval mass of each clutch between the two maternal groups at the start of the experiment $\left(F_{1,9}=0.6, P=0.47\right)$.

We found significant overall effects in our MANOVA for both maternal $\mathrm{Hg}$ exposure and predators, but no significant interaction between these factors (maternal $\mathrm{Hg}$ effect: Pillai's Trace $=0.472, \quad F_{5,24}=4.29, \quad P<0.01 ;$ predator effect: Pillai's Trace $=0.439, F_{5,24}=3.76, P=0.01$; interaction: Pillai's Trace $=0.122, F_{5,24}=0.67, P=0.65$ ). On average, animals with maternal $\mathrm{Hg}$ exposure were approximately $18 \%$ smaller at GS $42 \quad\left(F_{1,28}=5.9, \quad P=0.02\right.$; Fig. 1a) and $16 \%$ smaller at GS $46\left(F_{1,28}=3.8, P=0.06\right.$; Fig. 1b) than were their counterparts from mothers collected at the reference site. In contrast, maternal $\mathrm{Hg}$ exposure had no effect on survival to GS $46\left(F_{1,28}=1.2\right.$, $P=0.28$; Fig. 2$)$, larval duration $\left(F_{1,28}=0.8, P=0.38\right)$ or 


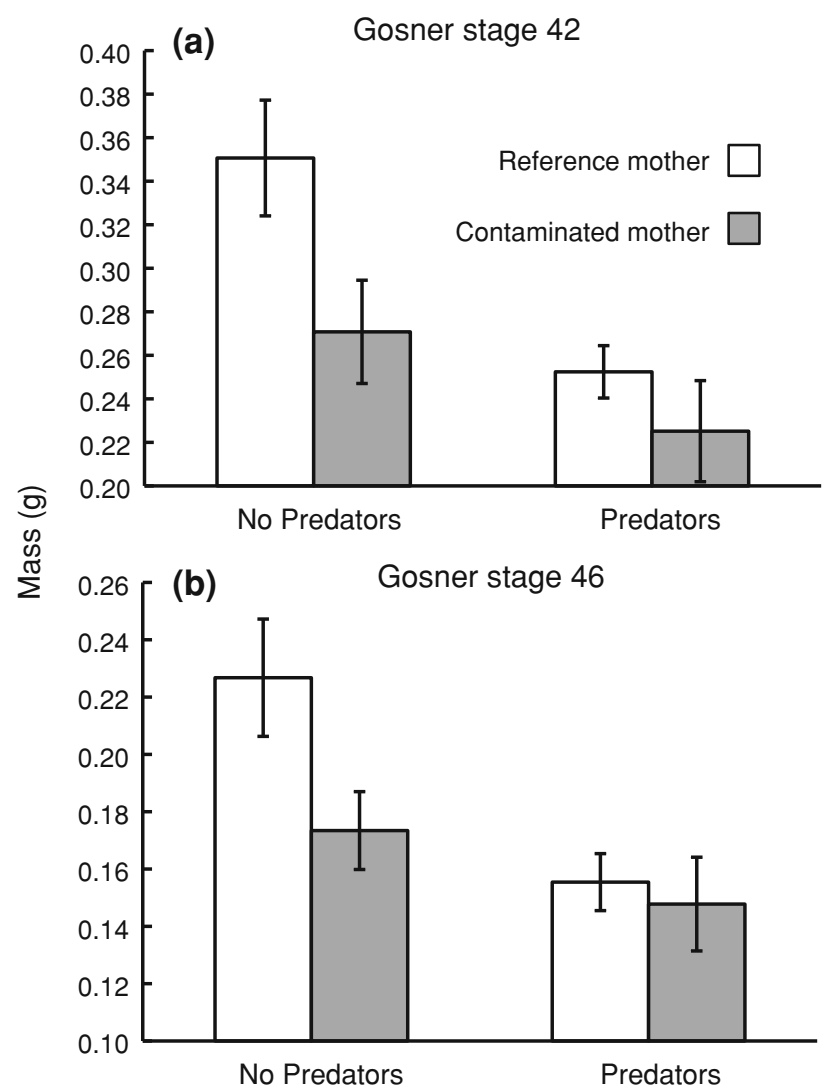

Fig. 1 Mass of American toad (Bufo americanus) larvae (mean \pm SE) from reference or contaminated mothers (maternal mercury exposure) in the absence or presence of 5 predatory odonates at a Gosner stage 42 , front limb emergence, and b Gosner stage 46, completion of metamorphosis ( $n=8$ for each experimental cross in $2 \times 2$ factorial design)

days required for tail resorption $\left(F_{1,28}=2.1, P=0.38\right)$. Animals reared in mesocosms with predators were approximately $23 \%$ smaller at GS $42\left(F_{1,28}=10.6, P<0.01\right.$; Fig. 1a) and $24 \%$ smaller at GS $46\left(F_{1,28}=9.7, P<0.01\right.$; Fig. 1b) than were their counterparts reared without predators. Additionally, there was some evidence that survival of tadpoles reared in the presence of predators was lower than that of tadpoles reared without predators $\left(F_{1,28}=3.7\right.$, $P=0.06$; Fig. 2). We found no effect of predators on larval duration $\left(F_{1,28}=0.00, P=0.95\right)$ or days required for tail resorption $\left(F_{1,28}=0.82, P=0.37\right)$.

In general, the prevalences of developmental abnormalities and injuries in tadpoles were influenced by predators, but not by maternal exposure to $\mathrm{Hg}$. For example, we found no effect of maternal $\mathrm{Hg}$ exposure or its interaction with predators on the proportion of GS 42 tadpoles having spinal malformations (maternal $\mathrm{Hg}$ effect: $F_{1,28}=0.3, P=0.86$; interaction: $F_{1,28}=0.08, P=0.78$; Fig. 3 ). In contrast, there was some evidence that the proportion of animals reaching metamorphosis with spinal malformations was greater for animals reared without predators than those reared in the

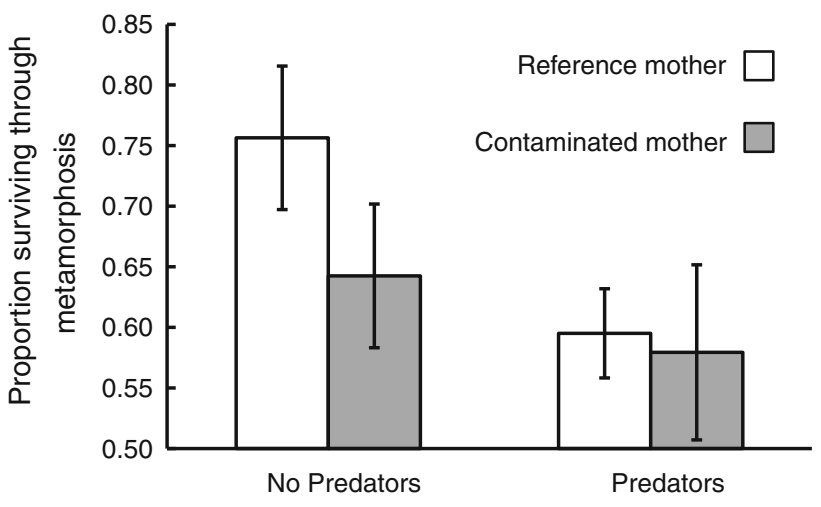

Fig. 2 Proportion of American toad larvae (mean \pm SE) surviving through metamorphosis from reference or contaminated mothers (maternal mercury exposure) in the absence or presence of 5 predatory odonates ( $n=8$ for each experimental cross in $2 \times 2$ factorial design)

presence of predators $\left(F_{1,28}=3.2, P=0.07\right.$; Fig. 3$)$. We found no effect of maternal $\mathrm{Hg}$ exposure or its interaction with predators on the proportion of metamorphosing tadpoles that had injuries (maternal $\mathrm{Hg}$ effect: $F_{1,28}=0.1$, $P=0.82$; interaction: $F_{1,28}=0.1, P=0.82$; Fig. 4$)$. In contrast, there was some evidence that predators influenced the prevalence of tadpole injuries $\left(F_{1,28}=2.9, P=0.09\right.$; Fig. 4$)$. Whereas no tadpoles that reached metamorphosis had injuries when they were reared in the absence of predators, $2.6 \%$ of tadpoles that reached metamorphosis were injured in tanks with predators. The injuries that we observed were consistent with attacks by odonates and included missing limbs, torn tails, and lacerations on the body. Although visual inspection of the mean proportion of animals having intact but stunted limbs seemed to indicate an increase in this phenomenon as experimental factors were added (Fig. 5), a Scherer-Ray-Hare test indicated no significant effect of maternal $\mathrm{Hg}$ exposure $\left(F_{1,28}=1.1, P=0.29\right)$, predators $\left(F_{1,28}=0.4, \quad P=0.53\right)$, or their interaction $\left(F_{1,28}=0.09, P=0.76\right)$. Lastly, we found a significant negative correlation between the number of tadpoles surviving to GS 42 and the amount of algae remaining on the mesocosms during metamorphosis $\left(R^{2}=0.26, \quad F_{1,30}=10.6\right.$, $P<0.01)$.

\section{Discussion}

Predation is an influential force in the structuring of many animal populations, and this is often true for larval amphibians. For example, the mere presence of caged predators can cause reductions in body size (Relyea 2007). However, when predators are allowed to interact freely with larval amphibians, they provide a clear demonstration of their influence on population dynamics via their effects on larval survival. We observed an average $16 \%$ reduction in 


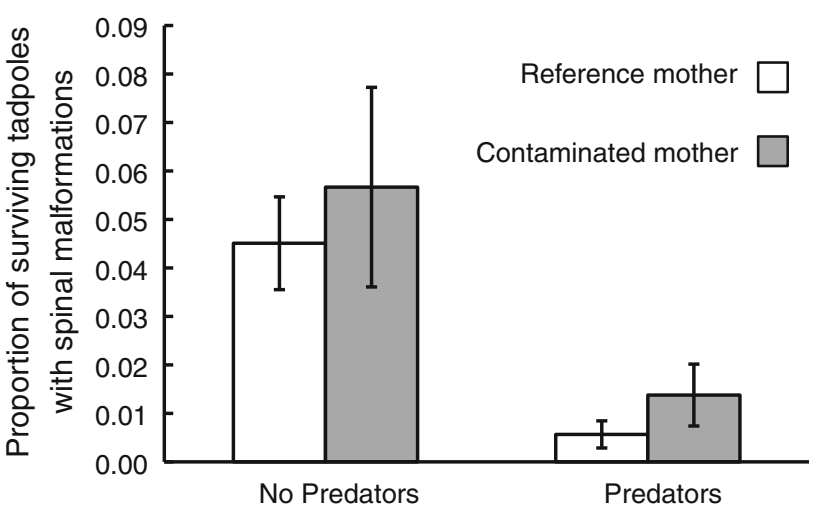

Fig. 3 Proportion of American toad larvae (mean \pm SE) surviving to Gosner stage 42 that had spinal malformations in the $2 \times 2$ factorial design of maternal mercury exposure (reference mothers or contaminated) and the absence or presence of 5 predatory odonates ( $n=8$ for each experimental cross)

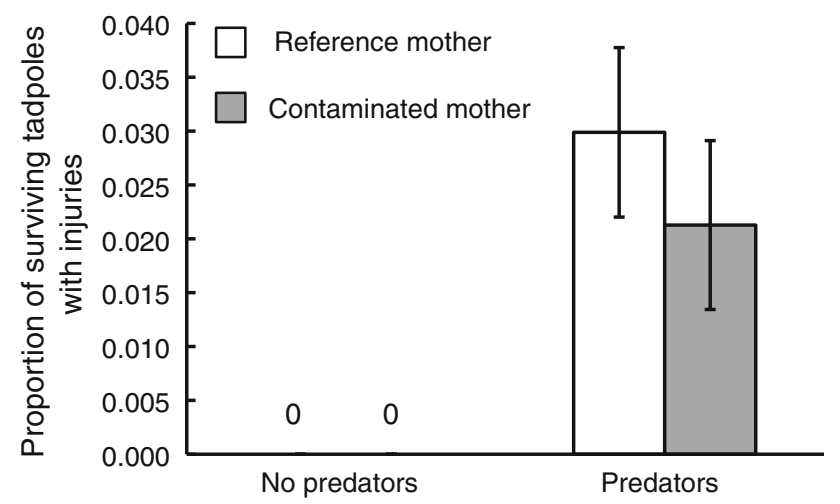

Fig. 4 Proportion of American toad larvae (mean \pm SE) surviving to Gosner stage 42 that had an injury of any kind in the $2 \times 2$ factorial design of maternal mercury exposure (reference mothers or contaminated) and the absence or presence of 5 predatory odonates ( $n=8$ for each experimental cross). No animals had injuries in the absence of predators

survival of offspring raised with free-roaming predators (Fig. 2). The impact of predators was further evidenced by a complete absence of injuries in any of the larvae raised without predators, in contrast to the approximate 3\% prevalence of injured larvae raised with predators, presumably survivors of failed predation by odonates (Fig. 4). A recent study similarly demonstrated that not all odonate attacks are lethal and, in some cases, that larvae survive with injuries that can affect post-metamorphic phenotypes (i.e., missing limbs; Ballengée and Sessions 2009). Additionally, the correlation of larval density at metamorphosis with algal density in the experimental mesocosms identifies a possible means of top-down effects of odonates on ecosystem structure via their direct role in larval mortality.

We found some evidence that suggested malformed tadpoles were selectively removed by predators. Specifically, the number of larvae surviving to metamorphosis with spinal malformations was more than five times greater when

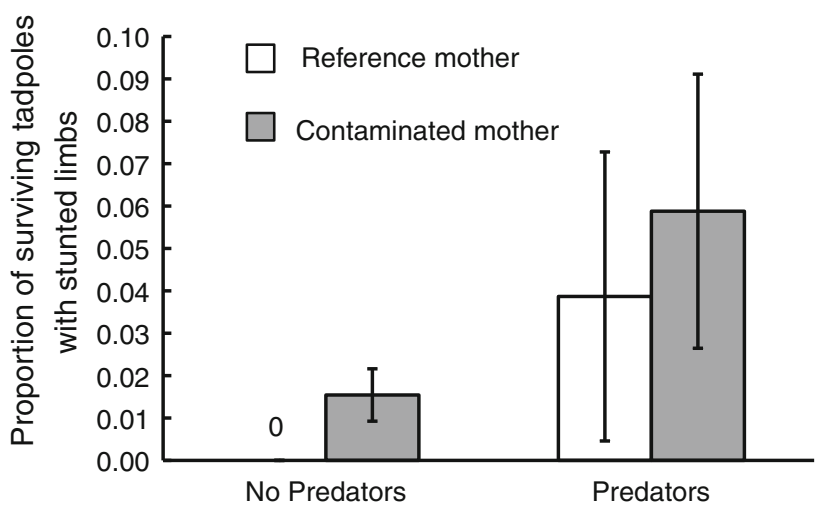

Fig. 5 Proportion of American toad larvae (mean \pm SE) surviving to Gosner stage 42 that had stunted limbs in the $2 \times 2$ factorial design of maternal mercury exposure (reference mothers or contaminated) and the absence or presence of 5 predatory odonates $(n=8$ for each experimental cross). No animals from reference mothers had stunted limbs when raised without predators

larvae were reared without predators (Fig. 3). Previous research has demonstrated that anuran larvae with spinal malformations swim slower than those without spinal malformations (Hopkins et al. 2000). Thus, we propose that the greater prevalence of spinal malformations in predator-free mesocosms implicates differential mortality of malformed amphibians when they are raised with predators. In other words, because swimming performance is poorer in malformed larvae, they presumably are more likely to succumb to attacks from odonates, leaving a lower proportion of malformed larvae in mesocosms containing predators. These results highlight one mechanism by which developmental aberrations might lead to increased mortality risk in amphibians.

We predicted that the interaction of maternal $\mathrm{Hg}$ and predators would have the greatest effect on offspring phenotype because amphibian predators can affect larval phenotypes via behaviorally mediated effects and because $\mathrm{Hg}$ is known to affect behavior (Heinz 1976, 1979). However, we found no significant interactions between the effects of maternal $\mathrm{Hg}$ and predators on any of our endpoints. There are several possible reasons why we did not find significant interactions of maternal $\mathrm{Hg}$ and predators. First, it is possible that maternal $\mathrm{Hg}$ simply had no effect on the outcome of predator-prey interactions. Second, it is possible that the five odonates in each mesocosm were feeding at a maximal rate throughout the study (i.e., they were satiated). Thus, although larvae negatively affected by maternal $\mathrm{Hg}$ may have been easier to catch and eat, predators were not necessarily able to handle and consume more of them. A third possibility is that any increase in mortality caused by maternal $\mathrm{Hg}$, albeit not statistically significant, may have combined with gradual removal by odonates to reduce predator-prey contact rates to a threshold below which 
predation was reduced. Given the large volume and size of the mesocosms, this is not entirely unlikely. Future work in which mesocosms have shallow water or greater predator densities may raise encounter rates and provide a better test of this hypothesis. A final possibility is that the combined effects of predators and maternal $\mathrm{Hg}$ may have reduced survival early in the larval period, but deleterious effects were offset by a competitive release that increased survival of remaining larvae throughout the latter stages of their development.

In our study, maternal $\mathrm{Hg}$ exposure resulted in smaller offspring. These size reductions were comparable in both direction and magnitude to the reductions observed in response to predatory odonates (Fig. 1). Reduction in body size due to predators is a widely reported phenomenon and has been demonstrated in earlier studies of American toads (e.g., Van Buskirk 1988; Wilbur and Fauth 1990). In contrast, reduced body size from maternal contamination represents the first evidence for such effects in amphibians. These maternal effects occurred in offspring from mothers with total blood $\mathrm{Hg}$ concentrations of $2,250 \mathrm{ng} / \mathrm{g}$ ww ( 1,598 ng/g ww MeHg based on known $\mathrm{Hg}$ speciation from Bergeron et al. 2010b). Using known correlations with whole-body tissues from an earlier study with this species at the South River, these concentrations equate to $655 \mathrm{ng} / \mathrm{g} \mathrm{THg} \mathrm{ww}$, or $347 \mathrm{ng} / \mathrm{g} \mathrm{MeHg} \mathrm{ww} \mathrm{(Bergeron}$ et al. 2010b). These levels exceed the whole-body tissue threshold-effect level of $200 \mathrm{ng} / \mathrm{g}$ ww MeHg identified for juvenile and adult fish by Beckvar et al. (2005) in their review of 10 studies. Additionally, Wiener and Spry (1996) concluded that sublethal effects to embryonic and larval stages of fish could occur at $1-10 \%$ of adult concentrations ( 2-20 ng/g ww MeHg based on Beckvar et al. 2005). For example, Matta et al. (2001) found reduced reproductive success in offspring of maternally-exposed mummichogs (Fundulus heteroclitus) when egg $\mathrm{MeHg}$ concentrations ranged from 10-630 ng/g ww. Our adjusted mean wet weight concentration of $\mathrm{MeHg}$ in American toad eggs was $3.6 \mathrm{ng} / \mathrm{g}$, a level on the low end of the estimated range for sublethal effects in fish. Also, our adjusted mean wet weight concentration of $\mathrm{THg}$ in American toad eggs of $7.5 \mathrm{ng} / \mathrm{g}$ was far below the 500-3,600 ng/g ww range in eggs known to cause hatching failure and aberrant behavior in birds (summarized in Wolfe et al. 1998; Scheuhammer et al. 2007).

There are at least two possible explanations for the smaller body size of maternally $\mathrm{Hg}$-exposed larvae. First, their smaller size may stem from the negative effects that $\mathrm{Hg}$ has on the endocrine system (reviewed in Tan et al. 2009), such that disruption of the endocrine system from maternal $\mathrm{Hg}$ exposure may have led to altered offspring development and thereby reduced growth rates. Alternatively, the smaller size of maternally-exposed larvae may have resulted from changes in offspring behavior due to the neurotoxic effects of $\mathrm{Hg}$. Mercury is a potent neurotoxicant that can affect animal behavior even when embryonic exposure is limited to maternal transfer (e.g., Heinz 1979; Alvarez et al. 2006). In amphibians, altered behavior can result in lower growth rates and smaller larvae (Relyea and Werner 1999). Reduced activity and grazing by tadpoles are behaviors that can be induced by predatory odonates, and which are linked to the production of smaller metamorphs (Relyea 2007). In this study, we found comparable reductions in body size from both odonates and maternal $\mathrm{Hg}$ exposure, consistent with a possible behavioral basis for the size reductions in both cases (e.g., reduced feeding activity). Ultimately, small body size at metamorphosis can reduce postmetamorphic survival and size at first reproduction, thereby diminishing lifetime reproductive success in amphibians (Berven and Gill 1983; Scott 1994).

Few studies of maternal effects in vertebrates have tracked offspring over time or through critical life history transitions, especially under varied ecological conditions such as the presence or absence of predators. In this regard, our research is among the first to demonstrate that maternal effects can significantly shape an offspring's phenotype through metamorphosis in a manner predicted to affect lifetime reproductive success, regardless of ecological conditions. Moreover, our work identifies the potential transgenerational effects that $\mathrm{Hg}$ accumulation can have in vertebrates via maternal effects on important phenotypic traits in offspring. Although ecological research often focuses on effects of aqueous or dietary exposure to a contaminant, the maternal effects of contamination represent an additional important route for toxicological effects in organisms. Future ecological research could combine studies of maternal and continuous dietary exposure to better understand relative contributions of contaminant exposure to animals under varying ecological conditions, especially since maternal and dietary exposure may frequently occur together.

Acknowledgments We thank D. Cristol, K. Carlson-Drexler, A. Condon, M. Howie, and C. Ramos for providing support and access to equipment used in mercury tissue analyses. We also thank J. Schmerfeld and the South River Science Team for their support. We thank the various landowners along the South River and the Waynesboro Parks and Recreation Department for allowing us access to sampling locations. We thank M. Nafus for illustrations used in the electronic supplementary material. Lastly, we thank K. McCaleb and J. McPherson for assistance with the experiment. Financial support was provided by E. I. DuPont de Nemours, Virginia Polytechnic Institute and State University, and by the National Science Foundation (NSF \# IOB0615361). C.M.B. was supported by the U.S. EPA STAR Graduate Fellowship (FP-9170040-1). EPA has not officially endorsed this publication and the views expressed herein may not reflect the views of the EPA. Research was completed with oversight from the South River Science Team, which is a collaboration of state and federal agencies, academic institutions, and environmental interests. Collecting permits 
and IACUC permission were obtained through W.A.H. at Virginia Polytechnic Institute and State University.

Open Access This article is distributed under the terms of the Creative Commons Attribution Noncommercial License which permits any noncommercial use, distribution, and reproduction in any medium, provided the original author(s) and source are credited.

\section{References}

Alvarez MdC, Murphy CA, Rose KA, McCarthy ID, Fuiman LA (2006) Maternal body burdens of methylmercury impair survival skills of offspring in Atlantic croaker (Micropogonias undulatus). Aquat Toxicol 80:329-337

Ballengée B, Sessions SK (2009) Explanation for missing limbs in deformed amphibians. J Exp Zool B 312:770-779

Beckvar N, Dillon TM, Read LB (2005) Approaches for linking whole-body fish tissue residues of mercury or DDT to biological effects thresholds. Environ Toxicol Chem 24:2094-2105

Bergeron CM, Bodinof CM, Unrine JM, Hopkins WA (2010a) Mercury accumulation along a contamination gradient and nondestructive indices of bioaccumulation in amphibians. Environ Toxicol Chem 29:980-988

Bergeron CM, Bodinof CM, Unrine JM, Hopkins WA (2010b) Bioaccumulation and maternal transfer of mercury and selenium in amphibians. Environ Toxicol Chem 29:989-997

Bernardo J (1996) Maternal effects in animal ecology. Am Zool 36:83105

Berven KA, Gill DE (1983) Interpreting geographic variation in lifehistory traits. Am Zool 23:85-97

Boone MD, James SM (2005) Aquatic and terrestrial mesocosms in amphibian ecotoxicology. Appl Herpetol 2:231-257

Dytham C (2003) Choosing and using statistics: a biologist's guide, 2nd edn. Blackwell , Malden

Fry DM (1995) Reproductive effects in birds exposed to pesticides and industrial chemicals. Environ Health Perspect 103:165-171

Gosner KL (1960) A simplified table for staging anuran embryos and larvae with notes on identification. Herpetologica 16:183-190

Heinz GM (1976) Methylmercury: second-year feeding effects on mallard reproduction and duckling behavior. J Wildl Manag 40:8290

Heinz GM (1979) Methylmercury: reproductive and behavioral effects on three generations of mallard ducks. J Wildl Manag 43:394401

Hopkins WA, Congdon JD, Ray JK (2000) Incidence and impact of axial malformations in larval bullfrogs (Rana catesbeiana) developing in sites polluted by a coal burning power plant. Environ Toxicol Chem 19:862-868

Hopkins WA, DuRant SE, Staub BP, Rowe CL, Jackson BP (2006) Reproduction, embryonic development, and maternal transfer of contaminants in the amphibian Gastrophryne carolinensis. Environ Health Perspect 114:661-666

Matta MB, Linse J, Cairncross C, Francendese L, Kocan RM (2001) Reproductive and transgenerational effects of methylmercury or Aroclor 1268 on Fundulus heteroclitus. Environ Toxicol Chem 20:327-335

Morin PJ (1983) Predation, competition, and the composition of larval anuran guilds. Ecol Monogr 53:119-138

Mousseau TA, Uller T, Wapstra E, Badyaev AV (2009) Evolution of maternal effects: past and present. Philos Trans R Soc Lond B 364:1035-1038
Mousseau TA, Fox CW (1998) Maternal effects as adaptations. Oxford University Press, New York

Myers GJ et al (1997) Effects of prenatal methylmercury exposure from a high fish diet on developmental milestones in the Seychelles Child Development Study. Neurotoxicology 18:819-829

Needham JG, Westfall MJ, May ML (2000) Dragonflies of North America. Scientific Publishers, Gainesville, p 939

Ohlendorf HM, Hothem RL, Welsh D (1989) Nest success, cause-specific nest failure, and hatchability of aquatic birds at seleniumcontaminated Kesterson Reservoir and a reference site. Condor 91:787-796

Ostrach DJ, Low-Marchelli JM, Eder KJ, Whiteman SJ, Zinkl JG (2008) Maternal transfer of xenobiotics and effects on larval striped bass in the San Francisco Estuary. Proc Natl Acad Sci USA 105:19354-19359

Pontier D, Gaillard J-M, Allainé D (1993) Maternal investment per offspring and emographic tactics in placental mammals. Oikos $66: 424-430$

Relyea RA (2007) Getting out alive: how predators affect the decision to metamorphose. Oecologia 152:389-400

Relyea RA, Werner EE (1999) Quantifying the relation between predator-induced behavior and growth performance in larval anurans. Ecology 80:2117-2124

Resetarits WJ, Wilbur HM (1989) Choice of oviposition site by Hyla chrysoscelis: role of predators and competitors. Ecology 70:220 228

Scheuhammer AM, Meye MW, Sandheinrich MB, Murray MW (2007) Effects of environmental methylmercury on the health of wild birds, mammals, and fish. Ambio 36:12-18

Scott DE (1994) The effect of larval density on adult demographic traits in Ambystoma opacum. Ecology 75:1383-1396

Semlitsch RD, Gibbons JW (1990) Effects of egg size on success of larval salamanders in complex aquatic environments. Ecology 71:1789-1795

Tan SW, Meiller JC, Mahaffey KR (2009) The endocrine effects of mercury in humans and wildlife. Crit Rev Toxicol 39:228-269

Unrine JM, Hopkins WA, Romanek CS, Jackson BP (2007) Bioaccumulation of trace elements in omnivorous amphibian larvae: implications for amphibian health and contaminant transport. Environ Pollut 149:182-192

USEPA (1998) Method 7473: mercury in solids and solutions by thermal decomposition, amalgamation, and atomic absorption spectrometry. Washington, DC, USA, pp 1-15

Van Buskirk $\mathbf{J}$ (1988) Interactive effects of dragonfly predation in experimental pond communities. Ecology 69:857-867

Wiener JG, Spry DJ (1996) Toxicological significance of mercury in freshwater fish. In: Beyer WN, Heinz GH, Redmon-Norwood AW (eds) Environmental contaminants in wildlife: interpreting tissue concentrations. Lewis, Boca Raton, pp 297-339

Wilbur HM (1987) Regulation of structure in complex systems: experimental temporary pond communities. Ecology 68:1437-1452

Wilbur HM, Fauth JE (1990) Experimental aquatic food webs: interaction between two predators and two prey. Am Nat 135:176-204

Wolfe MF, Schwarzbach S, Sulaiman RA (1998) Effects of mercury on wildlife: a comprehensive review. Environ Toxicol Chem 17:146-160

Wu J-P et al (2009) Residues of polybrominated diphenyl esthers in frogs (Rana limnocharis) from a contaminated site, South China: tissue distribution, biomagnification, and maternal transfer. Environ Sci Technol 43:5212-5217 